\title{
MOBILIDADE DO TRABALHO E CONTROLE SOCIAL: TRABALHOE ORGANIZAÇÕES NA ERA NEOLIBERAL
}

\author{
Fábio Guedes Gomes
}

\begin{abstract}
RESUMO
Este trabalho realiza uma releitura dos capítulos históricos de O capital, de Karl Marx, na perspectiva de trabalhar com o conceito de "mobilidade do trabalho", tal como este é desenvolvido no livro que serve de base teórica ao artigo: "Movilidad del trabajo y acumulación de capital", do autor francês Jean-Paul De Gaudemar. Esta obra é muito pouco conhecida no Brasil, sobretudo na área da economia política, contudo, ela é importante pela capacidade em aprofundar a concepção daquele conceito e por colaborar para a construção de uma interpretação mais acurada das determinações do capitalismo contemporâneo e de suas novas formas de exploração, tais como a flexibilização, a terceirização, a reengenharia etc. Sendo assim, o artigo procura, a partir do entendimento do conceito de mobilidade do trabalho, realizar algumas incursões em temas centrais do processo de acumulação capitalista, sobretudo em questões como desemprego e processos de trabalho que levam ao aumento da extração da mais-valia relativa e absoluta e que provocam, dessa maneira, a redução dos níveis médios de renda do grosso da população trabalhadora, o aumento da informalidade e a precariedade das condições de vida material. Pode observar-se que o esgotamento do padrão de acumulação capitalista, durante a transição entre a década de 1960 e 1970, promoveu mudanças profundas no modo de funcionamento do sistema, levando a formais mais indiretas de exploração e a controles culturais e ideológicos muito mais sofisticados e eficazes.
\end{abstract}

PALAVRAS-CHAVE: mobilidade do trabalho; controle social; capitalismo; modernidade; formas de exploração.

\section{INTRODUÇÃO}

O artigo busca fazer uma síntese do conceito de "mobilidade do trabalho" na perspectiva marxiana, apoiando-se na abordagem realizada por Marx nos capítulos históricos do primeiro livro de $O$ capital e, sobretudo, num trabalho pouco conhecido no Brasil, o do francês Jean-Paul De Gaudemar, Movilidad del trabajo y acumulación de capital, escrito originalmente em francês e publicado em 1975 (com uma versão em espanhol, de 1979). O objetivo geral é compreender melhor algumas das novas determinações sociais e econômicas do funcionamento do capitalismo e o processo de exploração da força de trabalho. Para tanto, faz-se necessário aprofundar melhor a perspectiva conceitual sobre a mobilidade do trabalho, tese central do trabalho de Gaudemar. Esse conceito, em linhas gerais, trata das formas como o capital produz, explora, faz circular e controla, tanto pelo lado da oferta como pela demanda, a força de trabalho como mercadoria essencial ao processo de acumulação capitalista.

Portanto, o texto está subdividido em quatro seções, além da conclusão. Na parte logo a seguir, apresentamos algumas questões gerais que consideramos importantes, tais como: o desemprego visto como um fenômeno global e como a principal característica do funcionamento do capitalismo contemporâneo; as reflexões acríticas e anistóricas desse processo, que forçam a compreensão da sociedade às explicações superficiais e naturalizam os determinantes estruturais da crise; o surgimento de novas formas e modelos de gerenciamento dos processos produtivos; a "obsoletização" das mercadorias (desgaste precoce), significando o empenho do capital em autovalorizar-se, encurtando o tempo tanto de produção como de consumo; a incorporação do progresso técnico como elemento central na luta pela competitividade e no aniquilamento dos concorrentes, ao mesmo tempo em que contribui para a validade da lei da tendência à queda da taxa de lucros. 
Na segunda parte do trabalho, procurar-se-á fazer uma releitura dos capítulos históricos de Marx, em $O$ capital, na perspectiva de encontrarmos elementos textuais e analíticos que demonstrem a importância que o tema "mobilidade do trabalho", na forma definida por Gaudemar, possui para Marx, e como ele pode ser retomado no sentido de ajudar na interpretação dos fenômenos contemporâneos de exploração capitalista. Importante, ainda nessa parte do trabalho, dissertar sobre como Gaudemar, até definir o conceito de mobilidade do trabalho, realiza uma discussão teórica de fôlego com as correntes da economia clássica e neoclássica, no intuito de mostrar as invalidades desse conceito sob o tratamento dos autores dessas correntes.

A terceira seção é uma continuidade da leitura dos textos de $O$ capital e de Gaudemar, na busca pela especificação do conceito de mobilidade do trabalho. Em seguida, discutimos, em termos gerais, alguns aspectos que afligem a sociedade contemporânea e que dizem respeito à maneira como a crise do capitalismo se expressa. Estamos preocupados principalmente em defender a idéia de que o desemprego e a deterioração das relações de trabalho são conseqüências das novas formas de exploração engendradas pelos novos instrumentos de produção e de controle, como a acumulação flexível e a terceirização. Esses processos criam condições propícias à expulsão de trabalhadores do processo produtivo, obrigando-os a somarem-se ao exército industrial de reserva, que, por sua vez, reforça as estruturas de controle social.

Portanto, esse mundo pós-moderno - ou pósindustrial, como queiram - ainda exprime, mais concretamente, as contradições da modernidade. Por isso, se aceitamos a natureza global da expansão do capital, abarcando territórios e acelerando o ritmo do tempo de sua produção, os problemas intrínsecos à sua lógica de funcionamento tornar-se-ão muito mais complexos, fazendo com que a produção do valor, neste estágio da história da sociedade capitalista, tenha implicações muito mais destrutivas. A encruzilhada em que a humanidade encontra-se, com relação à devastação do meio ambiente, ameaça romper as relações ontológicas entre homem e natureza definitivamente.

\section{REFLEXÃO GERAL}

Uma das questões mais proeminentes do funcionamento do sistema de produção capitalista é a da forma que o capital assume em seu ímpeto por acumular, o qual provoca o descarte em massa de trabalhadores do processo produtivo, com conseqüências negativas importantes para a sociabilidade em geral, sendo, a mais grave delas, a questão do desemprego. Esse problema assume uma dimensão muito mais negativa para a sociedade em geral à medida que o modo de produção tem procurado aumentar os ganhos de produtividade de forma intensa e sob bases tecnológicas sofisticadíssimas e muito mais complexas. Em estreita correlação com esse problema, estão outros, não menos importantes, como "favelização", fome, marginalização e aumento da criminalidade, desde os eventos mais banais até os delitos brutais e sintomáticos de uma sociedade em barbárie social.

Infelizmente, essa realidade não tem sido tratada de forma adequada, em conformidade com elementos estruturais determinantes. Por exemplo: a fome encontra sua explicação, muitas vezes, no baixo nível de educação de certas populações, impossibilitando às mesmas uma oportunidade de emprego ou ocupação; a criminalidade é imputada à falta de punição e de leis mais rígidas; a “favelização”, à falta de políticas públicas voltadas para o ordenamento mais racional dos solos nos centros urbanos. Atílio Borón (2001, p. 40-41), cientista político argentino, advertiu que, em tempos de crise, a reflexão tem ficado relativamente mais pobre e as propostas de solução dos grandes problemas da sociedade muito parciais. Isso pode ser esclarecido melhor quando ele afirma que, na agenda pública e nos principais fóruns que discutem a economia, o tema capitalismo saiu completamente da agenda.

A compreensão daqueles problemas mencionados, somados ao processo de intensificação das relações econômicas internacionais, com suas contradições e conflitos, só alcançará um grau de entendimento maior com um retorno à tradição da crítica à economia política como método de análise. Entretanto, diante do grau de complexidade que alcançou a sociedade capitalista, não é menos importante o papel de outras disciplinas, como 
História, Sociologia, Antropologia, Ciência Política etc. Fora dessa perspectiva, fica muito difícil chegar a métodos de investigação com maior capacidade explicativa da realidade, aptos a captarem as disfunções sistêmicas do sociometabolismo do regime de produção capitalista contemporâneo (cf. MÉSZÁROS, 2004) ${ }^{1}$. Com isso, certamente aumenta a possibilidade de recuperar o entendimento da sociedade e da economia num contexto histórico mais amplo, escapando dos riscos envolvidos nas abordagens que se destacam em naturalizar os problemas contemporâneos (KURZ, 1993, p. 204; BORÓN, 2001, p. 40-41).

Desde o começo do capitalismo, a questão do desemprego é uma característica essencial. Todavia, até poucas décadas, alguns de seus principais problemas podiam ser observados com mais nitidez nos países ditos subdesenvolvidos e do “Terceiro Mundo", ex-colônias produzidas no seio do desenvolvimento das regiões originárias do modo de produção. Nos espaços em que o capitalismo tinha alcançado um grau de amadurecimento elevado durante o século XX, as condições de vida de uma parte considerável das populações pareciam contrariar, definitivamente, as sombrias análises de alguns pensadores heterodoxos do século XIX, que observavam os limites da expansão capitalista e seus efeitos deletérios sobre a sociedade. Esse "Primeiro Mundo", distante da realidade socioeconômica da periferia capitalista, colocou-se como portador das transformações modernas depois da II Guerra Mundial, sob a liderança política e capacidade econômica dos Estados Unidos. Os sistemas de seguridade social que se formaram em quase toda a Europa ocidental selaram o pacto fordista (contrato social), taylorista (organização produtiva) e keynesiano (administração econômica e monetária) entre as nações capitalistas e dentro delas.

No entanto, depois de quase um século de reformismo burguês (MÉSZÁROS, 2004), de grandes e intensos conflitos (HOBSBAWM, 1995), de transição hegemônica (ARRIGHI, 1996) -

\footnotetext{
1 Por sociometabolismo, Mészáros compreende a estrutura orgânica de funcionamento da sociedade capitalista, para além da perspectiva meramente econômica. Assim como Marx, que definia o capital como uma relação social, Mészáros também escapa à interpretação limitada de uma abordagem positivista e economicista do regime de produção (cf. MÉSZÁROS, 2004).
}

britânica para norte-americana -, de declínio do “socialismo real” (KURZ, 1993) e de aprofundamento daqueles problemas acima mencionados, observamos uma sociedade mais instável, violenta e com um número de pobres que deixaria qualquer indivíduo do século XIX amedrontado. Em sua essência, a sociedade moderna burguesa é, inerentemente, instável e suscetível a crises econômicas e sociais sistêmicas, e cada vez mais freqüentes. A crise, portanto, é uma condição normal da modernidade (HARDT \& NEGRI, 2004, p. 221).

As contradições do sociometabolismo do capital são, portanto, levadas agora para o plano mundial. A expansão de suas estruturas produtivas sobre os mercados internacionais e a possibilidade de deslocamento do capital entre os espaços - a um ritmo potencializado pelas novas tecnologias de informática e por um sistema de transporte mais moderno e veloz (HARVEY, 1992) - permite-nos compreender certos fenômenos tidos como naturais - como, na verdade, conseqüências da expansão e acumulação capitalistas. O processo de controle social do trabalho pelo capital também se expande mundialmente. Os temas tidos como globais, como o meio ambiente e a fome, não passam de epifenômenos desse processo. A exaustão dos recursos naturais (sobretudo na área energética, a exemplo do petróleo) e a exploração de novas áreas estratégicas ditam o ritmo do processo de acumulação em escala planetária e os conflitos nacionais e internacionais (cf. FIORI \& TAVARES, 1997; FIORI, 1999; 2004; FIORI \& MEDEIROS, 2001; GONÇALVES, 2005). O crescimento do número de pobres no mundo não sendo mais privilégio dos países do "Terceiro Mundo" - significa que o exército industrial de reserva ganha dimensão global (cf. NAVARRO, 1997; MÉSZÁROS, 2005).

A interdependência dos mercados engendrada pelas redes de comercialização permite o aprofundamento da divisão internacional do trabalho e a promoção de novas condições de funcionamento para as atividades econômicas, notadamente as industriais e as de serviços. Sistemas em rede permitem que a fabricação de mercadorias intensifique-se de forma mais eficiente e produtiva, não importando, na maioria das vezes, o aspecto geográfico, ou seja, onde é produzido o produto e onde ele é consumido. O caso da empresa norte-americana de calçados Nike é emblemático, já que essa empresa fica apenas 
responsável por desenvolver os novos modelos, enquanto a fabricação dos mesmos fica a cargo de empresas terceirizadas, empregadoras de trabalho semi-servil em países da Ásia.

Uma das questões mais importantes dessa época, assim, é a capacidade que o sistema de produção capitalista alcançou de descartar trabalhadores em massa como decorrência do processo de permanente reestruturação produtiva, que promove a integração, das maneiras mais diversas, de trabalhadores com novas qualificações justapondo-se com as antigas, numa miríade de relações e práticas gerenciais (flexibilização, desregulamentação, terceirização, redução de custos e enxugamento organizacional (downsizing) etc.) que se traduzem, em última instância, na exploração mais intensa e na precarização das condições de trabalho (cf. MÉSZÁROS, 2005). Nesse sentido, pode-se dizer que estamos vivendo um período de intensas revoluções burguesas, porque a capacidade do capital e de suas classes dominantes concentrarem riqueza à custa dos que restam integrados (formal e informalmente) ao sistema produtivo é, indiscutivelmente, superior a qualquer outro período da história. Trata-se de uma máquina de exclusão (inclusão informal) de trabalhadores, a partir dos movimentos de elevação da composição técnica, ou seja, empregando, ad infinitum, novas tecnologias para dar continuidade ao processo de acumulação e concentração da riqueza.

Para os propósitos deste trabalho, é importante destacar o forte controle que o capital exerce sobre as relações de produção e sobre seus resultados, ou seja, sobre as condições de produção de mercadorias e lucros. Primordial, nesse sentido, torna-se a busca pelo monopólio sobre os distintos mercados estratégicos. Se na perspectiva marxiana, a mais-valia, base dos lucros capitalista, é resultado de uma relação social de exploração, tendo como fundamental o controle da força de trabalho e a expropriação do excedente, fruto justamente dessa força empregada, mas não paga. Paradoxalmente, ao mesmo tempo em que o trabalho é uma categoria central à produção e à acumulação capitalistas, ele vai sendo sistematicamente expulso do processo pela incorporação de novos arranjos técnicos. Daqui podem-se tirar algumas conclusões parciais. Uma delas é de que a própria “exclusão” dos trabalhadores do mercado de trabalho seja um instrumento de controle sistêmico, ainda que involuntário, no sentido imperativo (ARANTES, 2001, p. 318).

A seguir, nosso objetivo é apresentar os contornos gerais da perspectiva da mobilidade de trabalho que Gaudemar trabalha em seu livro. Numa primeira aproximação com essa categoria, poderíamos resumi-la como a capacidade do capital em produzir a mercadoria "força de trabalho”, em utilizá-la e, ao mesmo tempo, em criar condições de domínio e controle sobre a mesma. A exclusão pode ser um desses instrumentos, mesmo que imponha limites, como contradição fundamental, ao processo de reprodução do capital do ponto de vista da tendência à queda da taxa de lucro e do estreitamento dos mercados.

\section{A MOBILIDADE DO CAPITAL EM MARX}

Uma das grandes preocupações de Marx foi compreender o movimento e as determinações da sociedade capitalista em seu contexto histórico, diferenciando-a das sociedades pretéritas. A relação dialética entre o velho e o novo, entre as estruturas societais em decadência e a emergência, no seio das antigas, de novas realidades econômicas, sociais e políticas. Entretanto, o motor da história é atribuído à luta de classes. Para alguns, a chave da história. Marx e Engels escrevem isso explicitamente no Manifesto comunista. Não há um princípio de uma nova sociedade. As antigas estruturas vão, ao longo do tempo, forjando novas classes, que estabelecem novas configurações de poder ali aonde o declínio do sistema vai ficando inevitável e a capacidade de sustentar as estruturas das velhas classes vai definhando. As rupturas são momentos de contestação e subjugação da velha ordem pelas novas configurações sociais.

Para demonstrar como o sistema capitalista apresentava especificidades com relação aos sistemas anteriores, e como se estabeleceu como predominante, num contexto histórico bem definido de amadurecimento e ao mesmo tempo de crise do regime feudal na Europa, Marx apresenta as categorias essenciais que farão parte de seu método analítico.

Em carta direcionada a Ludwing Kulgelman (MARX, 1997, p. 179; 215-216), Marx sugere que seria mais fácil a compreensão de $O$ capital se a leitura iniciasse pelos capítulos mais históricos e descritivos (não a forma mais correta com certeza). Nesses capítulos, é reunida uma rica 
análise da formação da sociedade e economia capitalistas. A riqueza desses capítulos mais históricos pode ser também interpretada sobre diversos ângulos. No entanto, de uma maneira geral, é compreensível admitir que eles reúnam um conjunto coerente de temas que dão conta de descrever, analisar e criticar o processo dinâmico e conflituoso de constituição das relações de produção capitalista, seu aprofundamento, institucionalização e consolidação dos marcos objetivos e subjetivos dessa sociedade e seus determinantes econômicos.

Para Marx, a questão fundamental era compreender o processo de produção e circulação do capital, ou seja, seu desenvolvimento. Entretanto, essas condições devem estar determinadas, não de forma objetiva ou por obra dos indivíduos isoladamente, mas obedecendo aos interesses de classe que exigiam novas bases sociais. Os capítulos históricos são responsáveis por mostrar como as classes sociais no capitalismo vão constituindo-se e como o capital tem uma origem sangrenta. Ademais, dava conta de como o sistema desenvolve-se e estrutura-se à medida que sua essência transfigura-se de relações comerciais para as produtivas, até chegar ao sistema fabril maquinizado.

Como para ele a riqueza dessa sociedade traduzse numa "imensa acumulação de mercadorias", seria necessário estudar mais detidamente esse “detalhe” e descer ao nível da produção. Nesse trajeto, Marx elabora um sistema analítico que permitiu compreender e desnudar o fetiche das relações sociais da sociedade burguesa, que se observavam, geralmente, nas relações entre coisas, nas relações comerciais.

As mercadorias são as portadoras da mais-valia e sua comercialização é possível, porque elas expressam, ao mesmo tempo, valor-de-uso e valorde-troca. Ora, é porque as mercadorias reúnem essas condições que os mercados podem absorvêlas, porque elas podem ser produzidas e consumidas. Entretanto, a preocupação elementar para Marx era avançar em relação aos economistas clássicos ingleses e descobrir a verdadeira fonte da riqueza capitalista e minimizar o papel da circulação das mercadorias como fonte da riqueza, mesmo reconhecendo que o capitalismo comercial criou a indústria capitalista.

Os capítulos históricos e descritivos, entre outras coisas importantes, fazem parte da análise e descrição das condições concretas, das quais Marx parte para a construção das categorias abstratas de análise. Não bastam homens trabalhando, produzindo mercadorias e agindo cooperativamente no mercado, por meio das trocas, como percebia Adam Smith. É necessário construir as relações sociais de produção que possibilitem a acumulação de riqueza, e que as classes opressoras possam garantir o seu status econômico e seus espaços de poder, enquanto as classes subordinadas vendem sua força de trabalho em troca de salário e são integradas nas estruturas de produção capitalistas. Portanto, uma das questões-chave para Marx é demonstrar que, no capitalismo, a nova “escravidão" está assentada na liberdade do indivíduo e nas relações de assalariamento, em que os meios de produção (instrumentos de trabalho) e, fundamentalmente, as terras passam a ser propriedades privadas (por meio dos cercamentos na Inglaterra, por exemplo), para fins de exploração e acumulação.

É interessante, entretanto, o tratamento que Marx dá ao papel das colônias, especialmente ao caso particular da Nova Inglaterra. Para ele, as condições de "virgindade" - amplas fronteiras de terras livres e o desenvolvimento de comunidades assentadas na propriedade privada individual (sociedade atomista) - dessas regiões impediam o desenvolvimento capitalista, porque as relações de produção não tinham alcançado o grau de amadurecimento que permitisse o encontro do capitalista com a mão-de-obra assalariada, livre e sedenta por emprego, sob condições impostas pela falta de alternativas de sobrevivência. Dessa questão, deduz-se que o capital só pode ser compreendido como uma relação social em que a força de trabalho, como mercadoria, tem que ser produzida e controlada pelo capital com objetivos de exploração, assim como outra mercadoria qualquer: "A grande beleza da produção capitalista reside não só em reproduzir constantemente o assalariado como assalariado, mas também produzir uma superpopulação relativa de assalariados, isto é em relação à acumulação de capital. Assim, a lei da oferta e da procura fica mantida nos trilhos certos, a oscilação salarial, confinada dentro dos limites convenientes à exploração capitalista, e, finalmente, garantida a imprescindível dependência social do trabalhador para com o capitalista, uma relação de dependência absoluta, que o economista político em casa, na sua mãe-pátria, pode metamorfosear em relação 
contratual entre comprador e vendedor, entre dois possuidores igualmente independentes de mercadorias, o detentor da mercadoria capital e o detentor de trabalho" (MARX, 1989, p. 888).

Talvez essa passagem de $O$ capital resuma uma das grandes questões do livro de Gaudemar. A perspectiva desse autor, no geral, é buscar, com base no método dialético marxiano e no materialismo histórico, compreender como o capital produz e controla a força de trabalho, mercadoria vital ao sociometabolismo de acumulação. Ou seja: como o capital produz e faz circular, como qualquer outra mercadoria, o trabalho abstrato.

Para Gaudemar, a mobilidade de trabalho é uma categoria analítica que busca compreender como se estabelece a produção da força de trabalho como mercadoria, seu consumo de forma intensiva e extensiva, bem como essa força de trabalho é mobilizada em termos espaciais, setoriais e profissionais. A mobilidade, portanto, diz respeito às qualidades que a força de trabalho vai assumindo pelos imperativos da acumulação capitalista e, em última instância, como ela subordinada-se ao capital, na sua produção e circulação. No prólogo de seu livro, Gaudemar antecipa a sua problemática da seguinte forma: "En el fondo, mi pregunta es simple. En lenguaje marxista puede plantear-se así, mediante una interpretación de la teoría de la plusvalía: ¿Por qué se presta el trabajo o más bien la fuerza de trabajo de los hombres a todas las variaciones de duración, de intensidad, de productividad de donde nace la plusvalía, tanto en su forma absoluta como relativa? ¿Cómo designar el hecho de que se preste a semejante uso? Los conceptos de exploración y de plusvalía no indican más que el resultado de flujos de desviaciones o no suministran más que una representación simbólica de la jornada de trabajo [...] Es un hecho que la plusvalía representa la diferencia - apropiada por el capitalista - entre el valor de uso y el valor de cambio de la fuerza de trabajo [...] ¿de qué índole es pues esa fuerza de trabajo que se presta a semejante uso extensivo así como intensivo? ¿Cómo designar semejante cualidad? [...] Esa cualidad es precisamente lo que yo llamo movilidad del trabajo" (GAUDEMAR, 1979, p. 13; grifos no original).

A partir desses questionamentos, o autor empreende uma rica e erudita análise, iniciando pela crítica à economia política clássica, passando pelos neoclássicos e alcançando a perspectiva marxista, inclusive apresentando as concepções de Lênin e Rosa Luxemburgo sobre a temática e procurando apontar suas contribuições, limitações, bem como esses autores preocuparam-se com a questão da produção da mercadoria "força de trabalho".

Partindo daquela definição geral, podemos trabalhar os objetivos gerais a que Gaudemar compromete-se. Primeiramente, construir uma crítica à corrente neoclássica do equilíbrio geral e aos autores da teoria da localização industrial. Essas correntes pressupõem a existência de uma mobilidade perfeita do trabalho, defendendo que os trabalhadores têm capacidade de se deslocar por entre os espaços em busca de melhores condições de vida, que se traduzem em salários e rendas num nível mais elevado. Assim, a liberdade de escolha é atribuída ao trabalhador. Os neoclássicos admitem que os indivíduos comportam-se de maneira racional, podendo escolher entre as alternativas de emprego e as melhores condições materiais de vida.

Nessa perspectiva, então, o desemprego é algo transitório, porque da mesma forma que os salários são ajustáveis diante das condições da produção, a oferta de trabalho também o será. O equilíbrio walrasiano é alcançado quando os trabalhadores são empregados ao nível de salários vigente no mercado $^{2}$. Na possibilidade de existência de desemprego, os neoclássicos atribuem esse problema ao comportamento dos trabalhadores e à presença do Estado e/ou ao surgimento de monopólios. No caso do comportamento dos trabalhadores, as razões desdobram-se em duas basicamente: os indivíduos preferem o desemprego ao não aceitarem o nível de salários vigente (por razões, por exemplo, de um maior grau de sindicalização) ou por estarem migrando de um mercado de trabalho para outro (idem, p. 82-83).

\footnotetext{
2 O equilíbrio walrasiano é uma situação hipotética em que se supõe que todas as variáveis relevantes de um dado sistema econômico encontram seu ponto de equilíbrio. Nos mercados de trabalho, supõe-se que, a um dado nível de salários, a demanda por trabalhadores e a oferta de mão-deobra é compatível. Com alguma mudança, ou nos preços ou nos níveis de oferta e demanda, o ponto de equilíbrio desloca-se, tanto para baixo como para cima. Nessa condição hipotética, não há espaço nem para excesso, nem para escassez de mão-de-obra.
} 
Portanto, a força de trabalho, nessa perspectiva, é vista como um fator de produção qualquer e seu preço (salário) como determinado pelas leis de mercado, naturalmente, como viam Smith, Ricardo e Say. Assim, para Gaudemar, essa perspectiva teórica compreende a mobilidade do trabalho como simplesmente uma categoria que expressaria o ajustamento do mercado de trabalho (ou dos diversos mercados de trabalho), em busca do equilíbrio entre as forças de mercado num determinado nível de salários.

Ainda na linha de confronto com as idéias das correntes neoclássicas, Gaudemar dedica o terceiro e quarto capítulos do livro à crítica de alguns postulados teóricos das correntes tradicionais (Thunen, Weber e Losch) e mais contemporâneas da teoria da localização. Os primeiros buscam mostrar que as firmas são os agentes ativos da mobilidade, que são elas que buscam romper com as barreiras espaciais, com interesse de se localizarem em determinados ambientes geográficos. Esse movimento é sempre determinado por uma miríade de condições e aspectos institucionais, climáticos e geográficos. Nesse sentido, a massa trabalhadora assume um papel passivo no processo de crescimento econômico. Por outro lado, as correntes contemporâneas introduzem a mobilidade dos trabalhadores como resultado dos diferenciais de salário entre os espaços e das subjetividades que envolvem as decisões individuais dos trabalhadores. Nessas condições, a mobilidade da mão-de-obra não é tão perfeita como admitiam os neoclássicos margi-nalistas.

Na conclusão da primeira parte do trabalho, Gaudemar enfatiza, mais uma vez, as insuficiências da teoria neoclássica em compreender os fatos da realidade e a dinâmica capitalista, a partir dos axiomas que consideram o trabalho um fator de produção, uma mercadoria como qualquer outra, sujeita às variações de salários decorrentes do livre jogo das forças de mercado. As correntes contemporâneas do neoclassicismo buscam escapar um pouco dessa camisa-de-força, concentrando-se na multiplicidade das formas da mobilidade do trabalho e assumindo o caráter imperfeito da mobilidade. Entretanto, na opinião do autor, essas correntes não se distanciam muito do pressuposto central do equilíbrio de mercado walrasiano.

De qualquer forma, essas correntes de pensamento têm um forte componente de influência na determinação das políticas econômicas. Um dos pilares da atual filosofia liberal econômica é a concepção de que o desemprego tem, como uma de suas soluções, o aprofundamento dos mecanismos de funcionamento dos mercados e a flexibilização das relações de trabalho. Os autênticos economistas políticos burgueses defendiam os ideais do liberalismo econômico muito mais assentados na crítica moral e política da sociedade, e os neoliberais buscam resgatar algumas das idéias centrais desses economistas clássicos (cf. MÉSZÁROS, 2006, p. 260; SANTOS, 2007).

Além de resgatar e conservar o pensamento dos economistas clássicos, os neoliberais da contemporaneidade estabelecem condições normativas, com base nesses pressupostos, para o funcionamento das sociedades e nações. Paulani (2004, p. 124) concorda que a doutrina neoliberal inova e diferencia-se de suas bases filosóficas pelo pragmatismo político. Gaudemar demonstra os limites daquelas interpretações e afirma que seus resultados não dão conta de explicar a interdependência crescente entre a mobilidade dos indivíduos e os mercados de trabalho. Sobretudo, porque não levam em conta (por opção metodológica e ideológica) os aspectos subjetivos da relação dialética existente entre migrações e desenvolvimento capitalista: "Como dejar de pensar que el recurso analógico a los planteamientos de las ciencias llamadas exactas, tiene por función ideológica ocultar las relaciones sociales que actúan en los fenómenos" (GAUDEMAR, 1979, p. 35). Como o neoclassicismo, historicamente, insiste em aproximar-se das ciências exatas, com seus modelos matemáticos e objetividade cartesiana, não soa estranho que sua capacidade ideológica tenha como compromisso distanciar-se das subjetividades e relevar os conflitos sociais.

A opção de Gaudemar em explorar na literatura marxiana os elementos e categorias analíticas para explicar a mobilidade do trabalho, obedece à necessidade de tentar desmistificar a ideologia burguesa e o discurso teórico que trabalham no sentido de justificar o que ele chama de "mobilidade forçada”, ou seja, as várias condições impostas ao trabalhador para ser integrado ao sistema produtor de mercadorias, que vão desde o deslocamento espacial da mão-de-obra, passando pelas privações e pelo controle no ambiente das organizações capitalistas, até a necessidade incessante do trabalhador em buscar novas 
qualificações profissionais.

\section{GAUDEMAR E O CONCEITO DE MOBILIDADE DOTRABALHO}

Uma das tarefas cruciais para Marx foi desmistificar a idéia de um homem livre e soberano, egoísta e promotor do progresso de uma humanidade compreendida abstratamente, e o fez mostrando como o homem na sociedade moderna tem sua liberdade limitada pelas condições de apropriação dos meios de produção e pelo estabelecimento das relações de assalariamento. A preocupação de Gaudemar (idem, p. 200), no entanto, é desenvolver uma análise sobre como a própria acumulação de capital determina tanto as condições de demanda quanto de oferta de trabalho, demonstrando que o indivíduo trabalhador também constitui uma produção capitalista, pois somente tem a força de trabalho para vender em troca da sua própria sobrevivência e da de seus dependentes.

Nos capítulos históricos, Marx tem preocupação em analisar o processo de produção e acumulação de capital e, com esse processo, como a mercadoria "força de trabalho" vai sendo constituída em termos de volume necessário (empregada ou não) à produção social. Principalmente a partir da constituição das transformações concretas advindas da transição da ordem feudal para a burguesa.

Nesse sentido, o capítulo XXIV é um testemunho histórico de como capitalismo originou-se do exercício da força e do derramamento de sangue. Foi na transformação dos antigos escravos e servos em assalariados, com a troca de uma escravidão por outra (mudança de forma), juntamente com a dissolução da propriedade privada individual - por meio de formas bárbaras de violência, como expropriação, pilhagem, roubo e assassinatos - que nasceu o mundo maravilhoso de Adam Smith ${ }^{3}$. A violência foi parteira das relações de produção capitalistas: "Desta maneira, a população rural, violentamente desapropriada de suas terras, expulsa e transformada em vagabundos, foi chicoteada,

\footnotetext{
3 "A que se reduz, em última análise, a acumulação primitiva, a origem histórica do capital? Quando não é a transformação direta de escravos e servos em assalariados, mera mudança de forma significa apenas a expropriação dos produtores diretos, isto é, a dissolução da propriedade privada baseada no trabalho pessoal, próprio” (MARX, 1989, p. 879).
}

marcada a ferro e torturada, por meio de leis grotescas e terroristas, até submeter-se à disciplina necessária para o sistema do trabalho assalariado" (Marx apud KURZ, 1993, p. 34).

Entretanto, estabelecidas as condições sociais e econômicas impositivas que levavam os indivíduos para relações de assalariamento, a preocupação de Marx foi demonstrar como o sistema de produção, que tinha nas manufaturas e depois nas indústrias modernas a célula mater da geração do valor, continuou desenvolvendo-se e com ele a força de trabalho e as condições de sua exploração.

Metodologicamente, a disposição dos capítulos históricos permite observar esse plano de trabalho. Na terceira parte de $O$ capital, o capítulo referente à jornada do trabalho é uma análise de como os conflitos na base material de produção vão definindo e redefinindo os marcos jurídicos que norteiam os limites da exploração do trabalho excedente e do trabalho necessário. Esse aspecto é de fundamental importância, porque para o capital o que interessa, em geral, é que o valor de troca da força de trabalho (salário) seja inferior ao seu valor de uso, ou seja, que a força de trabalho possa produzir valores superiores ao custo de produção da mercadoria "força de trabalho", custo esse determinado pelas condições concretas do contexto histórico socioeconômico.

Por essa e outras questões, a discussão sobre mais-valia absoluta e relativa perpassa todos os capítulos históricos de $O$ capital. Na passagem da manufatura para a indústria moderna, os métodos empregados na produção foram sofisticando-se e as jornadas de trabalho, que já eram extensivas, tornaram-se ainda mais ${ }^{4}$, aprofundando as rivalidades entre capitalistas $\mathrm{e}$ trabalhadores por regulamentações na jornada de trabalho. Marx é tão cônscio desse processo histórico, que antes de anunciar o capítulo sobre a jornada de trabalho, define a categoria mais-valia absoluta como a quantidade de mercadorias

4 “O capital levou séculos, antes de surgir a indústria moderna, para prolongar a jornada de trabalho até o seu limite máximo, normal e, ultrapassando-o, até o limite do dia natural de 12 horas. A partir do nascimento da indústria moderna, no último terço do século XVIII, essa tendência transformou-se num processo que se desencadeou desmesurado e violento como uma avalanche" (MARX, 1989, p. 316). 
produzidas pelo prolongamento do dia de trabalho, isto é, das horas de trabalho não-pago. Mesmo anunciando o conceito de mais-valia relativa nesse instante também, Marx só lhe dará tratamento mais abrangente nos capítulos que antecedem sua análise do aprofundamento da divisão do trabalho e da passagem da indústria manufatureira para a moderna, com o emprego das máquinas e modernos equipamentos.

As relações entre trabalho pago e não-pago podem ser consideradas, portanto, como uma das primeiras determinações da mobilidade do trabalho nos termos de Gaudemar. É o momento em que o capital está decidindo sobre a vida dos trabalhadores, e o que lhe importa é apropriar-se do trabalho social. Esse controle subordina o trabalho ao capital e o salário passa a ser o cordão invisível da "escravidão", que lhe surrupia o trabalho excedente. Nesse sentido, a chamada ditadura do capital significa a maneira como são definidas a natureza do trabalho e as formas que ele assume depois que os empregadores contratam a força de trabalho. Acaba aí a liberdade do trabalhador. Da porta da empresa para dentro, sua autonomia é relativa e o que lhe resulta do esforço do emprego da sua força de trabalho é alienado. Esse tipo de controle social, Gaudemar (1979, p. 237-241) chama de "mobilidade do trabalho setorial”, quer dizer, aquele tipo de controle que permite que o capital possa fazer uso da força de trabalho, no ambiente de produção, como lhe convier, apenas respeitando os limites e condições impostas pelas instituições (regras jurídicas, nível de representação dos trabalhadores etc.).

Marx não deixa também escapar a capacidade que o capital tem de mover os trabalhadores com o objetivo de constituir o mercado de trabalho assalariado ou de abastecê-lo onde é necessário. Para Gaudemar, essa é uma das formas de mobilidade de trabalho, quando para sua reprodução, o capital controla e produz os fluxos migratórios. Trabalhadores potenciais são atraídos por novas oportunidades de emprego, impostas pelas condições inerentes à sobrevivência, precisando vender força de trabalho. Numa passagem de $O$ capital, Marx (1989, p. 303) já revelava como a força de trabalho, como uma mercadoria qualquer, circulava com o intuito de ser consumida: "Em certas épocas, de atividade febril, o mercado de trabalho se revela, sem dúvida, insuficientes, para atender a todas as solicitações de procura. Assim, por exemplo, em
1834 os fabricantes propuseram então aos membros da Poor Law Commission (Comissão de assistência aos pobres) mandar para o Norte a população excedente dos distritos agrícolas, afirmando que os fabricantes a absorveriam e consumiriam".

Podemos resumir a tese de Gaudemar da seguinte maneira, portanto: a mobilidade do trabalho é compreendida como um fenômeno que promove o deslocamento espacial, setorial e profissional do trabalhador, com o objetivo do capital explorar sua força de trabalho e acumular excedente econômico. Ao contrário de ser um sinônimo de liberdade, como querem os economistas políticos clássicos e neoclássicos, a mobilidade do trabalho significa, no contexto do sistema de produção capitalista, controle social, submissão e escravidão. O trabalhador, portanto, só é livre nos marcos das exigências da valorização do capital: "La movilidad del trabajo se convierte por tanto en el concepto que permite la representación de una reproducción ampliada libre de toda coacción - demográfica o proveniente de las rigideces del mercado del trabajo - exógena a su propio desarrollo" (GAUDEMAR, 1979, p. 222).

Por outro lado, a classe trabalhadora e suas ações não podem ser compreendidas nos marcos de um movimento apenas passivo no capitalismo. Muito pelo contrário, as lutas de classes envolvendo os trabalhadores marcaram fortemente a história do modo de produção, suscitando em seu funcionamento transformações estruturais e conjunturais, em alguns momentos favoráveis às classes trabalhadoras, em outros, mudanças muito mais importantes para a continuidade do processo de produção e de acumulação, sob bases radicalmente negativas para os trabalhadores.

\section{SOBRE AATUALIDADE DO CONCEITO DE MOBILIDADE DO TRABALHO}

Como exemplo mais simples (não desconsiderando a complexidade do problema logo a seguir), pode-se colocar em perspectiva o conceito de mobilidade do trabalho realizando uma ligação rápida com essas duas últimas citações, tanto de Marx quanto de Gaudemar. Elas lançam luz sobre a explicação, de modo geral, do fenômeno do processo de migração forçada e de levantamento de barreiras que impedem a livre circulação de trabalhadores entre as fronteiras internacionais. $\mathrm{O}$ exemplo da fronteira entre México e Estados 
Unidos é o mais emblemático nesse sentido. Depois da assinatura do Tratado de Livre-Comércio da América do Norte (Nafta), em 1994, envolvendo as economias daqueles dois países, mais o Canadá, o desemprego e exclusão social no México cresceram substancialmente, graças ao processo de desnacionalização da indústria e da forte presença de empresas exportadoras capitalintensivas. Presume-se que essas barreiras têm uma dupla função. Primeiramente, elas são responsáveis por controlar a entrada de mexicanos nos Estados Unidos, conforme sua economia necessita de mãode-obra barata ou não. Nesse sentido, o que parece ser uma proibição velada contra os imigrantes, é apenas funcional à dinâmica do capitalismo norteamericano. Por outro lado, o excedente de força de trabalho produzido no México cria as condições favoráveis para que os salários não sejam pressionados para cima, beneficiando as empresas monopolistas, principalmente multinacionais, ao mesmo tempo em que o setor privado fortalece seu controle operacional e ideológico sobre os trabalhadores integrados.

Essas circunstâncias revelam que exemplos como a fronteira entre o México e Estados Unidos reforçam a afirmação de Marx de que "a experiência mostra ao capitalista que existe uma população excedente, excedente em relação às necessidades momentâneas do capital de expandir o valor" (MARX, 1989, p. 305). Nesse caso em particular, Gaudemar chama a atenção para a importância da definição do conceito de superpopulação relativa, entendendo-o como o exército industrial de reserva que cresce, não necessariamente por causa do crescimento da população, mas é relativo porque também o incremento da população em condições de vender a força de trabalho decorre do desenvolvimento das condições de produção do capital social.

Numa outra perspectiva da mobilidade do trabalho, sublinhada por Gaudemar, mais precisamente no que diz respeito ao controle que o capital exerce sobre o trabalhador e sua força de trabalho no ambiente das organizações privadas, é importante salientar que o objetivo último é criar as condições genuínas para que o trabalhador aumente sua capacidade de criar valores excedentes. Como já é de conhecimento, isso pode acontecer de duas maneiras basicamente: por meio do aumento da jornada de trabalho ou do dispêndio de maior energia física e intelectual num mesmo período de tempo. Por exemplo: a redução do emprego da força de trabalho em certos setores pode provocar o aumento do grau de exploração dos que continuam integrados. Para Marx (idem, p. 348), portanto, “dentro de certos limites, a oferta de trabalho que o capital pode obter é, portanto, independente da oferta de trabalhadores”. Isso quer dizer que o capital tem um controle tanto interno às condições de emprego, quanto sobre a demanda por trabalhadores. Por outro lado, induzindo e promovendo as migrações, o capital estaria produzindo e controlando a oferta de força de trabalho em mercados distintos. É nesse sentido que as proposições de Gaudemar enfatizam a correta análise de Marx, tratando de explicar que o capital age em ambos os lados e que a acumulação e a concentração têm influência sobre a força de trabalho, tanto na sua demanda, quanto na sua oferta.

\section{V.1. Mudanças recentes na organização capitalista} e a mobilidade do trabalho

Desde a década de 1970, o capitalismo vem promovendo uma série de modificações estruturais na sua natureza produtiva. O que ficou conhecido como regime fordista de produção, com suas características radicais de separação dos trabalhadores dos seus meios de produção (cf. AGLIETTA, 1976) e aplicação dos métodos da administração científica taylorista, vem sofrendo mutações que implicam novos modelos de estruturação organizacional e de produção de mercadorias.

A crise do regime fordista de produção pode ser compreendida a partir do alcance de seus próprios limites. Com base em Aglietta, e correndo o risco de sermos bastante superficiais na explicação, três aspectos resumem os elementos dessa crise: 1) elevação do tempo de produção com desequilíbrios na cadeia de produção; 2) intensificação do trabalho com efeitos psicológicos e fisiológicos que traduzem-se no aumento das taxas de absenteísmo. Esses aspectos são responsáveis pela gradual e intensa degradação das condições de trabalho e 3) rompimento dos vínculos entre esforço e salário, com queda da produtividade e da motivação no ambiente de trabalho.

Esses aspectos internos ao funcionamento do sistema provocam efeitos externos que revelam as contradições do sistema em toda a sua plenitude, conforme mostra Aglietta. Os aspectos considerados por esse autor dizem respeito a: 1) 
o estrangulamento das condições de exploração da mais-valia, por intermédio do aumento da produtividade (mais-valia relativa). Esse processo vai refrear a expansão das relações de intercâmbio entre os diversos setores produtivos e 2) o Estado já não responde às necessidades de acumulação e entra em crise de legitimação (cf. O'CONNOR, 1977). Quer dizer, a antinomia entre funções de acumulação e funções de legitimação não corresponde mais às condições estruturais de funcionamento do capitalismo.

Algumas mudanças introduzidas a partir da década de 1970, no mundo organizacional, já apontavam para as novas determinações que caracterizariam o funcionamento e as relações sociais de produção. Dentre algumas mudanças, pode-se destacar: a eliminação da interrupção ou de desperdícios de tempo de trabalho ocioso; maior racionalização das operações de trabalho (reengenharia e qualidade total, redução de custos e enxugamento organizacional [downsizing] etc.); flexibilidade; multifuncionalidade da força de trabalho; modelo cooperativo de organização dos trabalhadores no ambiente de produção; descentralização da produção; perda de importância dos sindicatos, devido à fragmentação do processo de trabalho; e aumento substancial da informalidade.

Para os trabalhadores, essas mudanças implicaram uma série de novas condições que foram responsáveis por reconstituir relações de trabalho muito mais subjetivas. As relações de produção apresentam, na contemporaneidade, algumas características importantes, como: subcontratação (terceirização); trabalho familiar; trabalho por tarefas; tempo parcial. As práticas de gerenciamento são conduzidas por trabalhos em equipe e descentralizadas. Castel categoriza isso como "desfiliação", quer dizer, como o processo de destruição das relações salariais típicas da era fordista, assentadas no regime jurídico, principalmente, e na rigidez dos contratos de trabalho (Castel apud OLIVEIRA, 2003, p. 24).

Do ponto de vista institucional, quer dizer, no ambiente externo à produção, as mudanças mais significativas, em nossa opinião, são no sentido de promover maior liberdade às ações dos mercados e agentes privados e menor interferência do Estado na economia (sobretudo na promoção de políticas públicas de Estado que permitam o melhoramento das condições de sobrevivência societal). É importante frisar que essas mudanças não foram ocorrendo de maneira uniforme nos diversos países. Nas sociedades mais frágeis do sistema de poder internacional, elas assumiram claramente um status de estratégia de política econômica, que ficaram conhecidas como ajustamento neoliberal. Nesse caso, a América Latina transformou-se num laboratório das práticas dessas políticas ao longo das décadas de 1980 e 1990.

Conforme Harvey (2004,), o neoliberalismo é a restauração do poder de classe. Nessa perspectiva, os controles sociais sobre a força de trabalho, aliados às novas configurações produtivas das organizações, engendram uma série de determinações concretas que estabelecem novas realidades para a exploração de mais-valia (BRAGA, 2003, p. 24). Palavras-chave como competitividade, individualismo, empreendedorismo etc. tornam-se os novos símbolos do sucesso: "Num mundo darwiniano, o argumento neoliberal vinga, ficas para trás porque não és competitivo. Apenas sobrevives se te encaixares suficientemente bem. Não há nada sistematicamente errado. A falha está em ti. Não és suficientemente neoliberal” (HARVEY, 2004).

Isso cria margens para todo tipo de ocupação, principalmente no setor informal da economia, em que as cenas urbanas mostram jovens e crianças nas ruas fazendo malabarismos ou negociando todo tipo de "bugiganga". Limpadores de vidros de carros e deficientes auditivos misturando-se na busca pelos trocados dos motoristas. Nos pontos de ônibus, gente comercializando massas de pizzas, refrigerantes, balas, óculos e objetos falsificados. Um sem número de indivíduos que se misturam a uma paisagem caótica de intenso movimento de automóveis por causa da saturação do sistema de infra-estrutura de transporte público e aglomerações de mendigos e pedintes (cf. ARANTES, 2001, p. 342). Enquanto isso, a mídia burguesa não cansa de exibir reportagens e matérias sobre indivíduos que alcançaram o sucesso ou conseguiram escapar às situações de sobrevivência hostil, buscando "empreender” em atividades marginais a dinâmica econômica capitalista moderna. São casos excepcionais os quais são sempre mostrados como experiências que podem se multiplicar e generalizar-se, como se todos os excluídos tivessem as mesmas aptidões e oportunidades. 
Ao lado desses problemas, que se apresentam em quase todas as metrópoles e cidades de porte médio no Brasil, convivem as classes dominantes e os novos ricos que desfilam seus automóveis de luxo, nacionais e importados, consomem perdulariamente bens supérfluos e conspícuos em templos de moda de primeiro mundo (por exemplo, a loja Daslu) e deslocam-se, de maneira alternativa, pelos céus de uma das cidades que concentra o maior tráfico aéreo de helicópteros particulares do mundo (SIQUEIRA, 2005). Esses ingredientes somados dão naquilo que Oliveira (2003, p. 143) denominou "o ornitorrinco", quer dizer, "uma das sociedades capitalistas mais desigualitárias - mais até que as economias mais pobres da África que, a rigor, não podem ser tomadas como economias capitalistas -, apesar de ter experimentado as taxas de crescimento mais expressivas em período longo".

Mas o que faz essa sociedade reproduzir-se dessa forma? Quais as determinações contemporâneas que explicam estruturalmente o aprofundamento das desigualdades, o aumento da pobreza, o crescimento concentrado da riqueza e situações novas de maior repressão e controle social sobre as massas empobrecidas e sem expectativas? Isso é somente um problema brasileiro ou espraia-se por todo o mundo em que as forças capitalistas têm predominado, inclusive nos países desenvolvidos? São questões que guiarão a discussão a seguir.

V.2. Reestruturação produtiva, flexibilização e controle social

Os temas e questionamentos abordados anteriormente, na nossa perspectiva, só reforçam a validade das teses de Marx e Gaudemar sobre a mobilidade do trabalho, entendida esta como as formas que assume o capital para controlar, subordinar e reproduzir a força de trabalho como mercadoria especial.

Um aspecto importante diz respeito ao movimento do capital em flexibilizar as relações de trabalho, tornando o capital variável, o que Marx denominou "salários", dependente das condições impostas pela concorrência intercapitalista. Nesse caso, tanto Mészáros (2005) como Oliveira (2003) parecem concordar que a passagem do trabalho formal, como forma predominante do capitalismo “organizado", para o trabalho informal impõe novas condições à extração da mais-valia. Para esses autores, o aumento da produtividade engendrado pela introdução de novas tecnologias, não está sendo acompanhado por uma diminuição da jornada de trabalho.

Pelo contrário, Oliveira (idem, p. 136) afirma que surge desse processo uma contradição em tese: "A jornada da mais-valia relativa deveria ser de diminuição do trabalho não-pago”; mas ocorre justamente o que foi colocado acima, ou seja, "graças à produtividade do trabalho, desaparecem os tempos de não-trabalho: todo o tempo de trabalho é tempo de produção". Isso quer dizer que aquela diferenciação que Marx realiza entre trabalho pago e trabalho não-pago, correspondendo o salário ao primeiro e a mais-valia ao segundo, sendo a mais-valia relativa a intensificação da produtividade (com diminuição da fração do trabalho não-pago, devido à diminuição do tempo de produção graças às novas técnicas), essas condições, então, na contemporaneidade, desaparecem, porque o trabalhador, em condições de flexibilidade das relações (muitas vezes com a subcontratação), tem de trabalhar com base nos resultados alcançados com a venda das mercadorias. Quer dizer, o trabalhador só é (sub)contratado e recebe seu salário quando a mercadoria é realizada e transforma-se em dinheiro: “Assim, por estranho que pareça, os rendimentos dos trabalhadores agora dependem da realização do valor das mercadorias, o que não ocorria antes; nos setores ainda dominados pela forma-salário, isso continua a valer, tanto assim que a reação dos capitalistas é desempregar força de trabalho. Mas o setor informal apenas anuncia o futuro do setor formal [...] é quase como se os rendimentos do trabalhador agora dependesse do lucro dos capitalistas" (ibidem).

O movimento em direção ao desemprego da força de trabalho, para (sub)contratá-la em “condições especiais”, obedecendo aos padrões de flexibilidade, já ocorre nitidamente numa das fronteiras mais novas de acumulação de capital no Brasil: o ensino superior privado. Nele não é difícil visualizar novas relações de trabalho em que os professores são aproveitados conforme o número de alunos por sala e disciplinas que conseguiram ser efetivadas de acordo com a demanda. A utilização de força de trabalho nesse caso, portanto, obedece ao just in time. Ela deixa de ser um custo fixo (fix price), para se tornar flexível (flex price), como qualquer mercadoria. 
Como numa atividade econômica qualquer, e conforme rezam os manuais de microeconomia, a força de trabalho passa a ser introduzida no processo de produção quando o mesmo cresce. Como os tomates são custos variáveis para uma pizzaria, porque seu consumo só varia quando aumentam e diminuem a produção e as vendas de massas: "Como 'capital variável', os salários eram um 'custo'; como dependentes da venda das mercadorias/produtos, os rendimentos do trabalho, que não são mais adiantamentos do capital, já não são 'custo fixo'” (idem, p. 137).

Nessa proposição específica de Oliveira, é necessário fazer uma ressalva importante, apesar de ela estar correta em sua interpretação geral. Os rendimentos do trabalho não podem ser considerados um adiantamento do capital. O capital não adianta salários aos trabalhadores. Muito pelo contrário, é a força de trabalho, no seu uso durante a jornada de trabalho pré-determinada, que adianta ao capitalista, na forma de mais-valia, os recursos que colocam a produção em funcionamento. Isso quer dizer que o trabalhador só recebe salários ao fim da jornada de trabalho, depois de produzir as mercadorias e ter a exploração se concretizado. Os lucros capitalistas, a realização das mercadorias em dinheiro, isso sim, possibilita ao capitalista remunerar aquela fração do trabalho determinada pelas condições socioeconômicas históricas, quer dizer, pagar os salários. Assim, pode-se afirmar que realmente os salários obedeciam, nas relações de produção fordista, a certa rigidez imposta pelas condições de contrato e contexto histórico de afirmação dos sistemas de produção baseados no consumo de massas (contrato social).

Assim, o salário como um custo fixo da empresa foi um dos pilares do contrato social fordista-keynesiano-taylorista. A flexibilização e o crescimento do trabalho informal modificam estruturalmente as antigas determinações e seus respectivos sistemas de controle social. Dessa forma, a mobilidade do trabalho assume novos contornos e o controle social aumenta, porém, as suas formas tornam-se muito mais fetichizadas e reificadas. Podemos afirmar, então, que a flexibilização e a terceirização são os novos instrumentos de mobilidade do trabalho (cf. ARANTES, 2001, p. 332). Evidente que esses dois instrumentos são auxiliados por diversas inovações no campo da administração e da teoria da organização (HARDT \& NEGRI, 2004, p. 170).

Quanto a flexibilização, Gounet nos diz que a regulação salarial típica do capitalismo liberal permite a precariedade do emprego ao mesmo tempo em que exige do trabalhador compromissos com a empresa, ou seja, que se sinta parte dela; o indivíduo empregado deixa de ser trabalhador para ser "colaborador", "associado”, e outros rótulos que impõem uma falsa consciência de pertencimento às organizações: "[As] modalidades liberais de regulação da relação salarial, que privilegiam a flexibilidade, a precariedade do emprego, opõem uma barreira quase intransponível ao sentimento de engajamento do trabalhador com relação ao aperfeiçoamento da organização do trabalho e da qualidade dos produtos ou serviços de sua empresa. Os trabalhadores implicados deveriam sentir que seus interesses a longo prazo estão ligados aos da empresa. Aqui, não se avança; são necessárias contrapartidas; é necessário um grande compromisso" (Gounet apud BRAGA, 2003, p. 119).

Desde a época em que foram escritas essas linhas, novas estratégias de marketing surgiram, todas preocupadas em engajar os trabalhadores nas atividades das organizações. Isso demonstra que a mobilidade do trabalho também se estende à construção da hegemonia do capital no ambiente de trabalho, buscando identificar seus interesses particulares como interesses gerais também dos trabalhadores. Dessa forma, ao contrário do que Gounet afirmara, essas novas estratégias constroem identidades entre os trabalhadores e as organizações, e elas sofisticam-se na medida em que o tempo passa e as contradições e problemas no ambiente de trabalho tendem a agravar-se. Nesse sentido, o trabalhador deve sentir que seu interesse, no longo prazo, está ligado ao interesse de sua empresa (BRAGA, 2003, p. 159).

Uma dessas estratégias é o chamado "endomarketing”. Trata-se de ações de marketing direcionadas aos funcionários, estagiários, prestadores de serviços, fornecedores e empresas (sub)contratadas, que visam melhorar o desempenho das empresas. Essas ações realizamse no âmbito interno das empresas, que procuram sintonizar e sincronizar as ações de pessoal com as perspectivas das empresas, a fim de atrair clientes e torná-los fiéis aos seus produtos e 
serviços. Essa estratégia é muito mais sofisticada do que as técnicas puramente motivacionais ${ }^{5}$.

Essas estratégias tentam construir uma relação de lealdade dos trabalhadores (agora rotulados "colaboradores") para com as empresas, compartilhando objetivos "sociais" e empresariais da organização: "Os patrões precisam estar conscientes da importância das iniciativas dos trabalhadores. Os trabalhadores, conscientes de que seus interesses se vinculam aos da organização" (idem, p. 129). A velha utopia saintsimoniana do consenso, da negociação e do pacto rumo à harmonia dos interesses retorna por detrás das novas estratégias organizacionais.

Nesse sentido, tem razão Gounet quando sua reflexão acerca dessas novas relações de produção reforça o que discutimos anteriormente sobre o conceito de mobilidade do trabalho de Gaudemar: "O papel da negociação será o de alcançar acordos entre os parceiros sociais fazendo com que cada um tenha a sua parte. A negociação com soma nula cederá lugar a vantagens partilhadas. Em plano mais geral, uma análise mais fina das determinações do desempenho mostra que a organização do trabalho torna-se uma variável de comando essencial [...]. Tudo isso converge para a necessidade de implantar organizações de trabalho que qualifiquem para melhorar a competitividade" (Gounet apud BRAGA, 2003, p. 131, sem grifos no original).

O endomarketing, como estratégia de propaganda dessas novas organizações, comprova, entre muitos outros exemplos, o que

5 Emydio Palmeira, consultor em recursos humanos, em recente entrevista, mostra-se bastante entusiasmado com relação ao endomarketing: “O endomarketing é uma das peças mais importantes. Todas as empresas, sejam elas públicas, de capital privado, e ONG's [organizações nãogovernamentais], devem vender sua imagem para seus colaboradores. Isto significa tornar o funcionário aliado aos negócios, responsável pelo sucesso da corporação e igualmente preocupado com seu desempenho" (ENDOMARKETING AGREGA VALOR, 2005). Que maravilha o mundo do capital: o explorado deve ter consciência do sucesso da empresa com seu desempenho! $\mathrm{Ah}$, se realmente ele viajasse mais fundo em sua consciência e descobrisse que, mais do que um aliado, ele é o proprietário de fato da riqueza produzida, e que a sua apropriação privada por parte do capitalista é um roubo, expropriação, como diria Marx. Que ironia da estratégia capitalista convencer o explorado que é ele próprio responsável, com seu esforço, pelo sucesso do desempenho e dos lucros das organizações.
Hardt e Negri (2004) afirmam ao observarem o marketing como uma das ferramentas mais importantes do capitalismo pós-moderno. Para esses autores, "o pensamento pós-moderno é uma descrição excelente dos esquemas capitalistas de ideais de mercadoria e consumo, e por isso, oferece uma oportunidade para perfeitas estratégias de marketing” (idem, p. 170). Nesse caso, o endomarketing encaixa-se perfeitamente nos esquemas de valorização das organizações e de fetichização das relações de trabalho no contexto contemporâneo dos instrumentos de controle social das organizações: a flexibilidade e a terceirização.

O quadro ainda agrava-se para o lado dos trabalhadores ao considerar-se que, no capitalismo contemporâneo, a economia está sob o comando de verdadeiros conglomerados multi e transnacionais. Situação tão espetacular que, certamente, deixaria o próprio Lênin impressionado com a capacidade de o capitalismo vir produzindo monopólios e oligopólios dessa magnitude desde a edição de seu clássico Imperialismo: fase superior do capitalismo, na primeira década do século XX. Esses novos "leviatãs" atuam em diversos países ao mesmo tempo, em relações de produção verticalizadas e horizontalizadas que permitem uma capacidade de produção e faturamento que em muito superam o Produto Interno Bruto de vários países em conjunto (BÓRON, 1999, p. 45-49).

O peso dessas empresas em termos de definições de novas estratégias tem sido central para a transformação da força de trabalho e de sua exploração em termos variáveis, conforme a produção de bens e serviços realiza-se no mercado. Como foi visto acima, o custo da mão-de-obra, tornando-se variável (flex price), fortalece o poder dos capitais no que diz respeito às exigências e controle sobre os trabalhadores. Nesse sentido, crescem as pressões pela redução dos custos diretos, tanto da mão-de-obra, quanto das matérias-primas. Por outro lado, a percepção que se tem é de que essas empresas têm elevado seus gastos com custos indiretos, envolvendo sobremaneira estratégias de marketing e publicidade, serviços de financiamentos, pesquisa e desenvolvimento, inovação e tecnologias (cf. HARDT \& NEGRI, 2004). Simplificando, os gastos com custos diretos têm sido pressionados para baixo, assim, a remuneração da força de trabalho e as novas modalidades de contratação 
de trabalhadores são afetadas, em favor dos aumentos dos gastos e investimentos com custos indiretos, denominados no geral de overhead, na terminologia usual da administração. Nesse sentido, na determinação dos preços finais das mercadorias, tem contribuído sobremaneira os custos indiretos.

Dessas colocações, podemos tirar algumas conclusões prévias. Importa mencionar uma fundamental: a busca por atenuar a queda da taxa de lucro. $\mathrm{O}$ grau de concorrência por mercados e fronteiras de exploração capitalista exige o aumento desses gastos, que, por sua vez, determinam pressões sobre as relações de produção, provocando desemprego e exclusão social capitalista. Sendo assim, as formas de controle sobre os gastos diretos e, substancialmente, sobre a força de trabalho aumentam consideravelmente. $\mathrm{O}$ conceito de Gaudemar de "mobilidade do trabalho” ganha maior evidência quando observamos, portanto, as formas com que o capital tem estabelecido relações com o mundo do trabalho e como ele impõe, a este último, novas determinações que envolvem qualificação profissional, migrações e rearranjos produtivos internos e externos às organizações.

Mészáros, ao comentar sobre os efeitos deletérios do processo de flexibilização neoliberal levado a cabo no Japão, levanta uma questão importante e pertinente que torna o conceito de mobilidade do trabalho, de Gaudemar, uma categoria imprescindível para a compreensão das relações de produção contemporâneas. Para Mészáros (2005, p. 6), o capitalismo chegou num estágio em que, diante das necessidades impostas pela concorrência e diante da crise estrutural, existe uma tendência à equalização descendente da taxa de exploração diferencial. Suas proposições dizem respeito ao que afirmamos no início do trabalho, de que, com o crescimento do exército mundial de reserva, as formas de controle social do capital assumem contornos mais complexos e suas exigências ultrapassam as fronteiras transnacionais, misturando-se, da periferia capitalista para os países desenvolvidos e vice-versa: "As classes trabalhadoras de algumas das mais desenvolvidas sociedades 'pósindustriais' estão a adquirir uma antevisão da crueldade real do capital 'liberal' [...]. Assim, desenvolve-se a natureza real das relações de produção capitalistas: a impiedosa dominação do trabalho pelo capital está a torna-se cada vez mais evidente como um fenômeno global [...]. A compreensão do desenvolvimento e da autoreprodução do modo de produção do capital é absolutamente impossível sem o conceito de capital social total [...]. Analogamente, é absolutamente impossível entender os múltiplos e espinhosos problemas das variações nacionais e do trabalho socialmente estratificado se não se mantiver sempre em mente a estrutura necessária para uma avaliação adequada, nomeadamente $\mathrm{o}$ antagonismo irreconciliável entre capital social e a totalidade do trabalho" (idem, p. 5).

\section{CONCLUSÕES}

O conceito de mobilidade do trabalho, na perspectiva marxista, permite compreender questões fundamentais do processo de exploração capitalista. A transformação de indivíduos em meros vendedores de força de trabalho e o controle sobre essa mercadoria especial são temas centrais para Marx. Gaudemar busca, justamente, colocar no centro do debate contemporâneo essa categoria marxista: "En realidad, el tema de la movilidad del trabajo, sin duda considerado como menor por los marxistas, ya que es poco tratado - incluso mal tratado - por elles, me parece esencial con respecto a los temas mayores de El capital, de la teoría del modo de producción capitalista" (GAUDEMAR, 1979, p. 35).

Gaudemar é um autor da geração de 1960, que certamente presenciou os movimentos sociais na Europa do final da década. Sua preocupação em fazer a crítica tanto da teoria clássica quanto dos neoclássicos tinha um sentido político importante que em nossa interpretação diz respeito às necessidades de se contrapor à ideologia do desenvolvimento capitalista do pós-guerra. E isso fica evidente na forma como são tratadas, no livro, as estratégias do capital em atenuar os efeitos da tendência à queda da taxa de lucro, criando mecanismos e instrumentos de controle social e exploração da força de trabalho.

Não se pode desconhecer que as formas de exploração e de controle social modificaram-se ao longo desses últimos trinta anos - essa é uma questão importante. A história da luta de classes no capitalismo e o processo de exploração e acumulação devem ser estudados com base em aspectos metodológicos que dêem conta de compreender as novas determinações da sociedade burguesa contemporânea. Nesse caso, o conceito de mobilidade do trabalho é uma categoria analítica 
que nos permite perpassar os estágios do tempo histórico e compreender os fenômenos contemporâneos da exploração capitalista.

Nos tempos de Marx, a exploração era muito mais direta, ou seja, os trabalhadores e a força de trabalho ligavam-se mais explicitamente aos mecanismos de produção. Isso não quer dizer que Marx tenha negado ou não se importado com as formas indiretas. Mas as características do funcionamento do capitalismo industrial moderno engendravam situações de subordinação e submissão ao capital muito mais rígidas e forçadas. A cada momento histórico em que um padrão de acumulação, com suas características particulares de funcionamento e com um determinado nível de arranjo técnico, chega ao seu limite, o capital é instigado a realizar transformações estruturais na sua forma de funcionamento.

O esgotamento do padrão de acumulação capitalista, durante a transição da década de 1960 a 1970, promoveu mudanças profundas no modo de funcionamento do sistema. Essas mudanças determinaram novas formas de exploração que só são compreendidas por meio de um método de interpretação mais sistêmico, que abarque o conjunto das determinações econômicas, políticas e sociais do regime de produção capitalista. Essas novas formas têm assumido estratégias mais indiretas, determinando relações de produção fragmentárias, flexíveis e muito mais abstratas. Os sistemas de controle social são mais eficazes que os anteriores e passam, necessariamente, pela sofisticação dos controles ideológicos e culturais. O que muitos consideram como "pós-moderno", não passa de uma simbologia ideológica para reforçar a negação do que há de novo nas novas condições que estão implícitas na natureza da exploração capitalista e dos processos de controle social. O pós-moderno é apenas o ultramoderno, ou seja, trata-se da modernidade em sua plenitude.

Fábio Guedes Gomes (fguedes@ufba.br) é Doutor em Administração pela Universidade Federal da Bahia (UFBA) e Professor Adjunto da Faculdade de Economia, Administração e Contabilidade (FEAC) da Universidade Federal de Alagoas (UFAL).

\section{REFERÊNCIAS BIBLIOGRÁFICAS}

AGLIETTA, M. 1976. Regulación y crises del capitalismo. México : Siglo Veintiuno.

ARANTES, P. 2001. A fratura brasileira do mundo. In : FIORI, J. L. \& MEDEIROS, C. (org.). Polarização mundial e crescimento. Petrópolis : Vozes.

ARRIGHI, G. 1996. O longo século XX. São Paulo : Unesp.

BORÓN, A. 1999. Os “novos leviatãs” e a pólis democrática : neoliberalismo, decomposição estatal e decadência da democracia na América Latina. In : SADER, E. \& GENTILI, P. (org.). Pós-neoliberalismo II : que Estado para que democracia? Petrópolis : Vozes.

2001. A nova ordem imperial e como desmontá-la. In : SEONE, J. \& TADDEI, E. (orgs.). Resistências mundiais : de Seattle a Porto Alegre. Petrópolis : Vozes.
BRAGA, R. 2003. A nostalgia do fordismo : modernização e crise na teoria da sociedade salarial. São Paulo: Xamã.

FIORI, J. L. (org.). 1999. Estados e moedas no desenvolvimento das nações. Petrópolis : Vozes.

. (org.). 2004. O poder americano. Petrópolis : Vozes.

FIORI, J. L. \& MEDEIROS, C. (org.). 2001. Polarização mundial e crescimento. Petrópolis : Vozes.

FIORI, J. L. \& TAVARES, M. C. (org.). 1997. Poder e dinheiro : uma economia política da globalização. Petrópolis : Vozes.

GAUDEMAR, J.-P. 1979. Movilidad del trabajo y acumulación de capital. México : Era.

GONÇALVES, R. 2005. Economia política internacional. Rio de Janeiro : Elsevier. 
HARDT, M. \& NEGRI, A. 2004. Império. Rio de Janeiro : Record.

HARVEY, D. 1994. A condição pós-moderna. São Paulo : Loyola.

2004. Neoliberalismo e restauração do poder de classe. Disponível em : http:// resistir.info/varios/neoliberalis mo_ago04_port.html. Acesso em : 10.set.2004.

HOBSBAWM, E. 1995. A era dos extremos : o breve século XX, 1914-1991. São Paulo : Companhia das Letras.

KURZ, R. 1993. O colapso da modernização. São Paulo : Paz e Terra.

MARX, K. 1989. O capital. Rio de Janeiro : B. Brasil.

1997. O 18 Brumário e Cartas a Kugelmann. São Paulo : Paz e Terra.

MÉSZÁROS, I. 2004. O poder da ideologia. São Paulo : Boitempo.
2005. Desemprego e precarização : um grande desafio para a esquerda. Disponível em : http://www.lpp-uerj.net/outrobrasil/ Artigos_Destaque.asp?Id_Sub_Artigo=82. Acesso em : 10.out.2005.

2006. A teoria da alienação em Marx. São Paulo : Boitempo.

NAVARRO, V. 1997. Neoliberalismo y Estado del bienestar. Barcelona : Ariel.

O’CONNOR, J. 1977. USA : a crise do Estado capitalista. Rio de Janeiro : Paz e Terra.

OLIVEIRA, F. 2003. Crítica à razão dualista. $O$ ornitorrinco. São Paulo : Boitempo.

PAULANI, L. 2005. Modernidade e discurso econômico. São Paulo : Boitempo.

SANTOS, T. 2007. Del terror a la esperanza : auge e decadencia del neoliberalismo. Caracas : Monte Ávila.

SIQUEIRA, A. 2005. Mais hélices nos céus. Carta Capital, São Paulo, 2.nov.

\section{OUTRAFONTE}

Endomarketing agrega valor à empresa. 2005.

Jornal da Tarde, Salvador, 30.out., p. 4. 


\section{LA PENSÉE POLITIQUE DE HEGEL À LA LUMIÈRE DE SA PHILOSOPHIE DU DROIT}

\section{Wellington Trotta}

L'article analyse la pensée politique de Hegel à partir de sa « Philosophie du Droit », en faisant une présentantion systématique de ce que l'auteur a compris comme philosophie dont la politique était comme une conséquence inévitable, puisque son système théorique privilégiait l'unité logique. J’ai fait appel, dans l'élaboration de l'article, à un critère fort simples : présenter la pensée politique hégélienne à la lumière de son propre temps, prenant en compte les difficultés habituelles que tous ressentent pour exprimer des idées universelles à partir d'expériences particulières. Ainsi, je souhaite souligner que, bien que Hegel ait compris l'État dans la perspective de l'universel concret, son regard est prussien et tourné vers les problèmes de l'unité allemande. L'article est divisé en deux parties : la première est un exposé du contenu philosophique de l'auteur, tandis que la deuxième partie cherche à étudier systématiquement sa pensée politique, ayant comme borne sa « Philosophie du Droit ». Cette systématisation est envisageable puisque à l'origine le présent article intégrait mon mémoire de master, dans lequel j'ai pu établir une relation entre Hegel et la pensée de Marx de 1843, présentée dans la « Critique de la Philosophie du Droit de Hegel ». À la fin, en guise de conclusion, j'argumente que, même si l'ensemble des critiques de Marx sont importantes, la pensée hégélienne semble retracer non seulement l'État moderne, mais aussi l'État contemporain, surtout ceux des trente dernières années, où de plus en plus le pouvoir législatif perd, pour des raisons multiples, son rôle de législateur, et est remplacé par le pouvoir exécutif à qui revient l’approfondissement de l'universel au sein des particularités.

MOTS-CLÉS : Hegel ; Philosophie du Droit ; Marx ; État moderne ; philosophie allemande.

\section{MOBILITÉ AU TRAVAIL ET CONTRÔLE SOCIAL : TRAVAIL ET ORGANISATIONS À} L’ÈRE NÉO-LIBÉRALE

\section{Fábio Guedes Gomes}

Le travail réalise une relecture des chapitres historiques de Le capital de Karl Marx, dans la perspective de travailler sur le concept de « mobilité du travail », tel qu’il est développé dans le livre qui sert d'appui théorique à cet article : “Movilidad del trabajo y acumulación de capital”, du français Jean-Paul de Gaudemar. Cet ouvrage est peu connu au Brésil, surtout en économie politique. Pourtant, il est important pour la capacité d'approfondir la notion de ce concept et pour participer à la construction d'une interprétation plus poussée des déterminations du capitalisme contemporain et de ses nouvelles formes d'exploitation, comme la mobilité, la soutraitance, la reengineering, etc. Ainsi, l'article cherche, à partir de la compréhension du concept de mobilité du travail, à mener quelques incursions dans les thèmes essentiels du processus d'accumulation capitaliste, surtout dans des domaines comme celui du chômage et des procédés de travail qui mènent à l'accrue de l'extraction de plus-value relative et absolue qui déclenchent donc la réduction des niveaux moyens de revenu de la majorité de la population des travailleurs, l'accroissement de l'informalité et de la précarité des conditions de vie matérielle. On remarque que l'épuisement du modèle d'accumulation capitaliste, pendant la transition entre les années 1960-1970, a favorisé des changements profonds dans le mode de fonctionnement du système, produisant des formes plus indirectes d'exploitation et des contrôles culturels et idéologiques beaucoup plus sophistiqués et efficaces.

MOTS-CLÉS : mobilité du travail ; contrôle social ; capitalisme ; modernité ; forrmes d'exploitation. 


\section{HEGEL'S POLITICAL THOUGHT THROUGH THE PRISM OF HIS PHILOSOPHY OF LAW} Wellington Trotta

This article analyzes Hegel's political thought, through the prism of his Philosophy of Law. I present a systematic exposition of Hegel's concept of philosophy, which made politics a necessary consequence, given the fact that his theoretical system sought to establish a unitary logic. In elaborating the present text, I have employed a very simple criteria: to present Hegelian political thought through the prism of its own historical moment, taking the common difficulties that all of us experience in expressing universal ideas through singular experiences.. Thus, I would like to note that although Hegel thought of the State from the perspective of the universal concrete, his Prussian gaze is guided by his concern for German unity. The article is divided into two sections. The first provides an exposition of the thinker's philosophical content, whereas the second seeks to carry out a systematic study of his political thought, based on his "Philosophy of Law". This systematization is understandable since the present text was initially a part of my Master's Thesis in which I related Hegel and Marx's thought in the 1843 period, as expressed in the latter's "Critique of Hegel's Philosophy of Law". Lastly, in conclusion, I argue that notwithstanding the relevance of Marx's set of criticisms, Hegelian thought seems not only to provide a portrait of the modern State but also the contemporary one, particularly that of the last 30 years, a period in which legislative power has lost its legislative role, increasingly substituted by the executive which in turn has been confronted by the task of increasing the universality within its particularities.

KEYWORDS: Hegel; Philosophy of Law; Marx; the Modern State; German philosophy.

LABOR MOBILITY AND SOCIAL CONTROL: WORK AND ORGANIZATIONS IN NEOLIBERAL TIMES

\section{Fábio Guedes Gomes}

This paper engages in a re-reading of the historical chapters of Karl Marx's Capital, in the interests of working with the concept of "labor mobility" as it has been developed in the book that serves as the underlying theoretical reference for this article: the French scholar Jean-Paul de Gaudemar's "Labor mobility and capital accumulation". The latter work is little known in Brazil, particularly within the area of Political Economy. Nonetheless, it is extremely important, given its approach to the concept and contribution toward building a more accurate interpretation of the determinants of contemporary capitalism and its new forms of exploitation (flexibilizing, sub-contracting, reengineering, etc.) Thus, through a heightened understanding of the concept of labor mobility, we seek to make some incursions into central themes on the process of capital accumulation, with particular concern for issues such as unemployment and labor processes that lead to increased extraction of relative and absolute surplus value and that consequently lead to a drop in the wage levels of a large part of the working classes, increasing the informality and precariousness in their material conditions of life. We are able to observe that the exhaustion of patterns of capital accumulation during the transition from the 1960s to the 1970s has promoted profound changes in the way the system functions, leading to more indirect forms of exploitation and to more sophisticated and efficient forms of cultural and ideological control.

KEYWORDS: labor mobility; social control; capitalism; modernity; forms of exploitation. 